\title{
Factors associated with routine mass antimicrobial usage in fattening pig units in a high pig-density area
}

\author{
Jordi CASAL ${ }^{\mathrm{a}, \mathrm{b} *}$, Enric MATEU ${ }^{\mathrm{a}, \mathrm{b}}$, William MeJÍA ${ }^{\mathrm{b}}$, Marga MARTín ${ }^{\mathrm{a}, \mathrm{b}}$ \\ ${ }^{a}$ Centre de Recerca en Sanitat Animal (CReSA), Universitat Autònoma de Barcelona, \\ 08193 Bellaterra, Barcelona, Spain \\ ${ }^{\mathrm{b}}$ Departament de Sanitat i Anatomia Animals, Edifici V, Universitat Autònoma de Barcelona, \\ 08193 Bellaterra, Barcelona, Spain
}

(Received 10 July 2006; accepted 9 December 2006)

\begin{abstract}
One hundred and seven fattening pig units randomly selected in Catalonia (Spain) were surveyed during 2001-2003, in order to determine the frequency of the prophylactic use of antimicrobials and mass treatments against respiratory and enteric disease outbreaks. Logistic regression and regression tree analysis were done to determine the factors associated with the on-farm mass antimicrobial usage. Fifty-eight per cent of the surveyed farms used mass antimicrobial prophylaxis; among them, 39\% used two or more antimicrobials. The more frequently administered drugs were colistin, beta-lactams and tetracyclines. Fattening units from strict finishing farms were more likely to use antimicrobials than farrow-to-finish farms $($ Odds Ratio $=11.7)$ and farms with changing facilities were less likely to use these compounds $(\mathrm{OR}=0.17)$. In the event of a respiratory disease outbreak, most farms applied mass treatment and $46 \%$ used two or more compounds, with tetracyclines, beta-lactams and sulphonamides being the most popular ones. Mass treatment with several compounds in case of respiratory problems was significantly related to the use of growth promoters on the farm $(\mathrm{OR}=4.3)$. If an outbreak of an enteric disease occurred, most farms resorted also to a mass treatment and $48 \%$ used two or more drugs. The most frequent antimicrobial agent for the treatment of enteric disease was colistin. Fattening farms $(\mathrm{OR}=6.9)$ and operations that perform routine antimicrobial prophylaxis $(\mathrm{OR}=2.0)$ were more likely to use more than one antimicrobial agent for enteric diseases.
\end{abstract}

antimicrobial agents / fattening pig units / prophylactic usage / regression tree

\section{INTRODUCTION}

Veterinary use of antimicrobial compounds is one of the most controversial issues in the antimicrobial resistance debate that is being held nowadays. While therapeutic use for diseased animals is probably not questionable, mass prophylaxis or growth promotion usages are more controversial. Thus, there is a general agreement that a rational use of antimicrobials implies

*Corresponding author: jordi.casal@uab.es a clear definition of situations in which an antimicrobial treatment is indicated and has no reliable alternatives (i.e. vaccines, etc.) and to which extent non-therapeutic use in animals is advisable or not ${ }^{1}$.

Most countries are now restricting the non-human usage of antimicrobial drugs

\footnotetext{
${ }^{1}$ World Health Organization, Use of antimicrobials outside human medicine and resultant antimicrobial resistance in humans. Fact sheet no. 268 [on line] (2002) http://www.who. int/mediacentre/factsheets/fs268/en/print.html [consulted 5 February 2006].
} 
and, for instance, the European Union has banned the use of antimicrobial compounds as growth promoters. Some data from several countries showed that the use of these drugs can significantly increase resistance rates $[2,8,9,12]$. The magnitude of the transfer of resistances from animals to humans is not well known and while some studies suggest that it is a big problem $[10,15]$ other researchers suggest that this transfer represents a low risk [14].

Few data are available about veterinary use of antimicrobials in mass prophylaxis in pig farms $[3,6,7]$. In the present report, we examined a number of swine farms in Catalonia (Spain), one of the European areas with the highest pig densities, regarding routine mass antimicrobial usage in fattening units and determined the factors related to this use.

\section{MATERIALS AND METHODS}

\subsection{Questionnaire and survey}

The study was conducted during 2001-2003 as a survey on swine farms of Catalonia (Spain) that had fattening pigs. The data were collected in relation to another study, aimed at evaluating the epidemiology of enteric diseases and antimicrobial resistance to antimicrobials. The total population of the region was some 7128 farms. Amongst these, 109 were randomly selected, using a stratified sampling by counties, and surveyed. This sample was large enough to detect relationships between mass medication and any risk factor with $20 \%$ presence in the population with a $7.5 \%$ error and $95 \%$ confidence. Sample size was calculated using WinEpiscope [17].

For each farm, a detailed questionnaire including 84 questions about facilities, management, biosecurity and health aspects of the fattening herd, was completed by a personal interview during a farm visit with the assistance of the veterinary practitioner in charge of the farm. The more relevant questions are summarised in Table I. A final section of the questionnaire was devoted to routine antimicrobial usage for growth promotion (the survey was conducted before growth promoters were banned in the EU), antimicrobial prophylaxis and therapy in all age groups of the farms (routine use was defined as the application of at least one treatment of antimicrobials in $\geq 90 \%$ of animals during the last six months). In this paper, we focus on the results related to fattening animals (animals aged between $8-10$ weeks and slaughter). Number and type of antimicrobials used simultaneously in the same animals were recorded. Drugs that are usually used in combination, such as trimethoprim + sulphametoxazol and lincomycin + spectinomycin, were considered in this paper as a single compound.

\subsection{Data analysis}

Collected data were first subjected to a descriptive univariate analysis and then to a bivariate analysis comparing frequencies of each variable that can act as a risk factor with four dependent dichotomous variables: the use of prophylactic antimicrobials (farms that use one or more antimicrobials as a routine before any sign of disease appear), the use of growthpromoters, the use of antimicrobial agents in therapeutic mass treatments for enteric illnesses and finally their use for respiratory problems. The number of farms that did not administer antimicrobials for the mass treatment for respiratory and enteric diseases was very scarce (6 and 10 farms respectively); in these cases, the comparison was established between the use of two or more antimicrobial agents used simultaneously versus none or only one antimicrobial (including standard combinations). 
Table I. Most relevant questions included in the survey.

\begin{tabular}{|c|c|c|c|}
\hline Variable & Number of responses & Median & Minimum-maximum \\
\hline Number of fattening pigs & 107 & 1000 & $60-3800$ \\
\hline Number of sows (if present) & 44 & 250 & $90-800$ \\
\hline \multirow[t]{2}{*}{ Mean mortality rates (last 6 months) } & 73 & $5 \%$ & $1 \%-12 \%$ \\
\hline & Number of responses & & lues \\
\hline Type of farm & 107 & Farrow-to-finish $=44$ & Fattening units $=63$ \\
\hline Livestock other than pigs raised & 107 & Yes $=34^{*}$ & No $=73$ \\
\hline Changing facilities available & 99 & Yes $=15$ & No $=84$ \\
\hline Dogs and/or cats on the farm & 107 & Yes $=69$ & No $=28$ \\
\hline Clean working clothes available & 98 & Yes $=85$ & $\mathrm{No}=13$ \\
\hline Clean boots available & 98 & Yes $=80$ & No $=18$ \\
\hline Shower available & 98 & Yes $=42$ & No $=56$ \\
\hline Toilet available & 98 & Yes $=83$ & No $=15$ \\
\hline Bird proof nets & 96 & Yes $=76$ & No $=20$ \\
\hline Rodent control program & 90 & Yes $=86$ & $\mathrm{No}=4$ \\
\hline Water source & 81 & Public net $=45$ & Private wells $=36$ \\
\hline Water analysis (potability) & 88 & Yes $=71$ & No $=17$ \\
\hline Production system & 74 & All-in/all-out $=60$ & Continuous flow $=14$ \\
\hline Cleaning of pens between batches & 99 & Yes $=95$ & No $=4$ \\
\hline Disinfection of pens between batches & 99 & Yes $=91$ & No $=8$ \\
\hline Dividing walls & & Solid $=74$ & Discontinuous = 24 \\
\hline Ventilation & 98 & Mechanical $=16$ & Natural $=82$ \\
\hline Type of drinkers & 97 & In-feeder 69 & Off-feeder $=28$ \\
\hline Drinkers & 100 & Water bowls $=25$ & Nozzle drinkers $=75$ \\
\hline Feeding system & 98 & Automatic $=83$ & Manual = 15 \\
\hline Feedstuff & & Purchased $=57$ & Produced $=35$ \\
\hline Sewage drainages & 92 & Open $=12$ & Closed $=80$ \\
\hline Sewage tanks & 97 & One $=39$ & More than one 58 \\
\hline Routine diagnosis of death causes & 80 & Yes $=70$ & No $=10$ \\
\hline Methods of diagnosis & 70 & Necropsies $=68$ & Laboratory $=2$ \\
\hline
\end{tabular}

* Cattle: 18 , fowl: 12 , horses: 2 , rabbits: 2 .

This part was done with Epi-Info 2002 ( $\chi^{2}$ for discrete variables and ANOVA/Kruskal-Wallis for continuous variables such as herd size). Variables yielding $p$-values less than 0.25 were included in a logistic regression analysis done by the backward stepwise method using SPSS 12.0 (SPSS Inc., Chicago, USA). For relationships that presented strong co-linearity $(p<0.05)$ only the variable with the "a priori" stronger biological association with the antimicrobial usage 
was retained. All variables included in the regression analysis were dichotomous. Continuous variables were previously recoded to dichotomous ones using the median as a cut-off.

To determine the profiles of antimicrobial usage in the studied farms, variables were also analysed by means of regression trees using Answer Tree 3.0 (CRT method) (SPPS Inc.). The minimum number of data in a given node was set to 10 , and the improvement minimal limit was 0.01 .

\section{RESULTS}

\subsection{Descriptive results}

Table I shows the results of the most relevant questions included in the survey.

\subsubsection{Growth-promoters}

One hundred nine farms were surveyed; two of them were discarded because less than $50 \%$ of the questions were answered. Thus, the final number of examined farms was 107,44 were farrow-to-finish farms and 63 were fattening farms. Information about growth promoters was obtained on 98 farms: forty fattening farms $(41 \%$; $95 \%$ confidence interval (95CI): 32\%-50\%) used them. On these farms, salinomycin was the only drug administered.

\subsubsection{Prophylactic use of antimicrobials}

Sixty-two farms (58\%; 95CI: $48 \%-67 \%$ ) used antimicrobial compounds as a routine in-feed or in-water prophylaxis for fatteners between two and six months. Amongst those farms, 15 (14\%; 95CI: $8 \%-22 \%$ ) used only one compound, 28 (26\%; 95CI: 18\%-36\%) used two compounds, 11 (10\%; 95CI: $6 \%-18 \%$ ) used three drugs and on three farms $(3 \%$; 95CI: $1 \%-9 \%)$ four or more antimicrobials were used. The other five farms routinely applied antimicrobials, but no data were provided about how many drugs and which ones were administered. The most common drugs administered to pigs were colistin, beta-lactams, tetracyclines and sulphonamides (Tab. II).

\subsubsection{Therapeutic use of antimicrobials against respiratory problems}

When asked about the administration of empirical mass treatments before having a definitive diagnosis, 92 farms did so (under veterinary advice) when confronted with a respiratory outbreak (out of 98 farms that answered the question). Forty-four farms (45\%; 95CI: $35 \%-55 \%$ ) used only one compound, 21 used up to two compounds (21\%; 95CI: $13 \%-30 \%)$ and 24 used three or more simultaneous drugs $(24 \%$; 95CI: $15 \%-34 \%)$; in three cases no detail of the number of drugs was provided. The most popular antimicrobials were tetracyclines (81 farms), beta-lactams (30 farms) and sulphonamides (26 farms) (Tab. II). On 26 farms, combinations of beta-lactams and tetracyclines were used for mass treatment. For empirical individual therapy of respiratory disease, 24 farms $(22 \%)$ used only one antimicrobial and $51(48 \%)$ used two or more compounds.

\subsubsection{Therapeutic use of antimicrobials against digestive problems}

Eleven farms did not answer the question of how many antimicrobial drugs were used for enteric disease. Eighty-six farms out of 96 responses (90\%; 95CI: $83 \%-96 \%$ ) did antimicrobial mass treatments routinely in case of an outbreak. The most common route of administration was drinking water and the number of compounds used was variable. Thus, 
Table II. Frequency of the use of mass antimicrobial prophylaxis or treatment in fattening pigs of Catalonia: total number and (percentage) ( $n=107$ farms).

\begin{tabular}{lccc}
\hline & & \multicolumn{2}{c}{ Empiric mass treatments* } \\
\cline { 2 - 4 } & Prophylactic & Respiratory & Enteric \\
\hline No treatments & $45(42.1)$ & $6(6.1)$ & $10(10.4)$ \\
1 compound & $15(14.0)$ & $44(44.9)$ & $32(33.3)$ \\
2 & $28(26.2)$ & $21(21.4)$ & $25(26.0)$ \\
3 & $11(10.3)$ & $23(23.5)$ & $25(26.0)$ \\
$>3$ & $3(2.8)$ & $1(1.0)$ & $1(1.0)$ \\
Undefined (1 or more) & $5(4.7)$ & $3(3.1)$ & $3(3.1)$ \\
Unknown/not mentioned & 0 & 9 & 11 \\
\hline Colistin & $27(28.1)$ & 0 & $64(66.7)$ \\
Tetracyclines & $16(16.7)$ & $81(84.4)$ & $1(1.0)$ \\
Beta-lactams & $22(22.9)$ & $30(31.3)$ & $28(29.2)$ \\
Sulphonamides & $15(15.6)$ & $26(27.1)$ & $1(1.0)$ \\
Lincomycin & $13(13.5)$ & $1(1.0)$ & $7(7.3)$ \\
Macrolides & $13(13.5)$ & $11(11.5)$ & $5(5.2)$ \\
Tiamulin & $8(8.3)$ & $2(2.1)$ & $25(26.0)$ \\
Aminoglycosides & $2(2.1)$ & $1(1.0)$ & $28(29.2)$ \\
Unknown/not mentioned & 5 & 4 & 3 \\
\hline
\end{tabular}

*Without a definitive diagnosis.

32 farms used one compound (33\%; 95CI: $23 \%-43 \%), 25$ used two antimicrobials (26\%; 95CI: $17 \%-35 \%)$ and the other 26 farms administered up to three antimicrobials (27\%; 95CI: $18 \%-36 \%)$. The most frequently used compound for mass treatment was colistin (Tab. II). Individual therapeutic treatments were less common (62 farms) and most frequently enrofloxacin or tiamulin were administered.

In contrast with these results, only 17 farms (16\%) used mass treatments for meningitis outbreaks and none used it for arthritis outbreaks. In these two disease groups, beta-lactams were the antimicrobial of choice for both mass and individual treatments.

\subsection{Logistic regression results}

\subsubsection{Growth-promoters}

The routine use of growth-promoters presented a significant relationship with the production system in the logistic regression analysis: fattening farms presented an Odds Ratio (OR) $=2.8$ (95CI: 1.2-6.9) compared with farrow-to-finish farms and with the number of pigs $(\mathrm{OR}=0.35,95 \mathrm{CI}: 0.15-0.82)$, due to the more frequent use of growth-promoters in the small fattening units.

\subsubsection{Prophylactic use of antimicrobials}

The variables that were linked to the use of a routine antimicrobial prophylaxis were the production system (only fatteners versus farrow-to-finish: $\mathrm{OR}=11.7,95 \mathrm{CI}$ : 4.1-33.3) and to have changing facilities (OR $=0.17$, 95CI: 0.03-0.79) (Tab. III).

\subsubsection{Therapeutic use of antimicrobials}

In the logistic regression, the use of more than one compound for the mass treatment of respiratory diseases was only 
Table III. The results of the logistic regression analysis for routinely antimicrobial prophylaxis and treatments in fatteners in 107 fattening pig units of Catalonia.

\begin{tabular}{|c|c|c|c|c|c|c|}
\hline $\begin{array}{l}\text { Dependent } \\
\text { variable }\end{array}$ & Independent variable & Odds Ratio & $\mathrm{CI}_{95 \%}$ & Coefficient & S.E. & alue (Wald's) \\
\hline $\begin{array}{l}\text { Use of growth } \\
\text { promoters (1) }\end{array}$ & $\begin{array}{l}\text { Only fatteners (1) vs. } \\
\text { farrow-to-finish (0) }\end{array}$ & 2.8 & $1.2-6.9$ & 1.05 & 0.45 & 0.021 \\
\hline vs. no use (0) & $\begin{array}{l}\text { Herd size: } \leq 1000 \text { (1) } \\
\text { vs. }>1000 \text { finishers }(0)\end{array}$ & 0.35 & $0.15-0.82$ & -1.07 & 0.44 & 0.016 \\
\hline & Constant & & & 0.62 & 0.71 & 0.38 \\
\hline $\begin{array}{l}\text { Use of } \\
\text { prophylactic }\end{array}$ & $\begin{array}{l}\text { Only fatteners (1) vs. } \\
\text { farrow-to-finish (0) }\end{array}$ & 11.7 & $4.1-33.3$ & 2.46 & 0.54 & $<0.001$ \\
\hline $\begin{array}{l}\text { antimicrobials } \\
\text { (1) vs. no }\end{array}$ & $\begin{array}{l}\text { Changing facilities: } \\
\text { Yes (1) vs. no (0) }\end{array}$ & 0.17 & $0.03-0.79$ & -1.80 & 0.80 & 0.024 \\
\hline use (0) & Constant & & & 0.35 & 0.73 & 0.64 \\
\hline $\begin{array}{l}\text { Respiratory } \\
\text { problems: } \\
\text { Use of } 2 \text { or more } \\
\text { antimicrobials }\end{array}$ & $\begin{array}{l}\text { Use of growth } \\
\text { promoters (1) vs. } \\
\text { no (0) }\end{array}$ & 4.3 & $1.8-10.3$ & 1.45 & 0.50 & 0.001 \\
\hline $\begin{array}{l}\text { (1) vs. } 1 \text { or no } \\
\text { use (0) }\end{array}$ & Constant & & & -0.72 & 0.30 & 0.015 \\
\hline $\begin{array}{l}\text { Enteric } \\
\text { problems: }\end{array}$ & $\begin{array}{l}\text { Only fatteners (1) vs. } \\
\text { farrow-to-finish (0) }\end{array}$ & 6.9 & $2.3-20.5$ & 1.94 & 0.55 & $<0.001$ \\
\hline $\begin{array}{l}\text { Use of } 2 \text { or more } \\
\text { antimicrobials } \\
\text { (1) vs. } 1 \text { or no }\end{array}$ & $\begin{array}{l}\text { Use of prophylactic an- } \\
\text { timicrobials (1) vs. no } \\
\text { (0) }\end{array}$ & 2.0 & $1.3-3.2$ & 0.71 & 0.24 & 0.003 \\
\hline use $(0)$ & Constant & & & -1.85 & 0.50 & $<0.001$ \\
\hline
\end{tabular}

$\mathrm{CI}_{95 \%}=95 \%$ Confidence interval of the odds ratio; S.E. $=$ Standard error.

related with the use of growth promoters $(\mathrm{OR}=4.3$, 95CI: $1.8-10.3)$ (Tab. III).

Regarding the usage of antimicrobial agents for the mass treatment of enteric diseases, we found that fattening farms $(\mathrm{OR}=6.9$, 95CI: $2.3-20.5)$ and operations that perform routine in-feed or in-water antimicrobial prophylaxis $(\mathrm{OR}=2.0,95 \mathrm{CI}$ : 1.3-3.2) were more likely to use more than one antimicrobial agent for the mass treatment of enteric diseases.

\subsection{Decision tree analysis}

The use of the regression tree analysis methodology to profile farms with regards to routine antimicrobial prophylaxis showed that farms could be initially divided according to the use of growth promoters. Thus, farms that used growth promoters were more likely to apply antimicrobial prophylaxis $(75 \%$ versus $48 \%$ ) and to use higher number of drugs $(75 \%$ used two or more compounds compared with 20\%). Among these farms, antimicrobial prophylaxis was more common in farms having only fattening units (96\% used antimicrobials) than in farrowto-finish farms $(25 \%)$. For farms that did not use growth promoters, antimicrobial prophylaxis was less frequent in those cases where mortalities were lower than 3\% compared with farms having moderate to high mortality rates. Figure 1 shows the results of the regression tree.

In the regression tree, profiling of farms according to the number of antimicrobials used against respiratory problems shows 


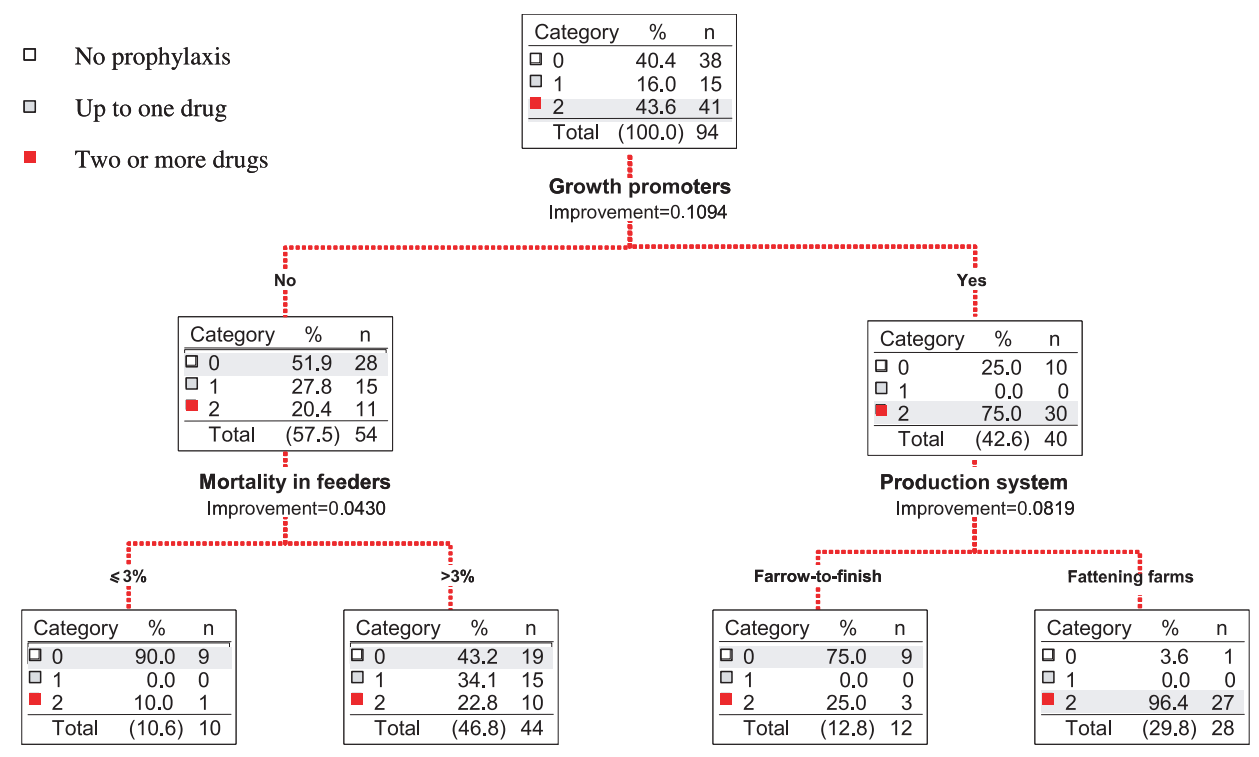

Figure 1. Regression tree profiling the prophylactic use of in-feed and/or in-water antimicrobials in finishers in Catalonia $(n=107)$. (A color version of this figure is available at www.edpsciences.org/vetres.)

that farms could be initially classified by the production system. Fattening farms that added growth promoters to feed also resort to a higher number of antimicrobials to treat respiratory diseases (Fig. 2).

The results of the regression tree also show that fattening farms were more likely to use two or more antimicrobials against enteric problems than farrow-tofinish farms did. The farm census was also related with enteric treatments. Thus, fattening farms with less than 1350 pigs were more likely to use multiple antimicrobials than larger operations. Figure 3 shows these results.

\section{DISCUSSION}

The aim of this study was to explore which variables could be associated with a routine use of in-feed or in-water antimicrobial prophylaxis in fattening pigs as well as to figure out which profiles were related with the number of antimicrobials used on the farm.

Forty of the surveyed farms used salinomycin as growth promoters, with this being the only product used on these farms. The use of salinomycin was more frequent in fattening units than in farrow-to-finish farms, and this was especially true in small fattening farms. This fact can indicate a major use of this compound in less professional farms and, as discussed below, a higher use of mass medications on this type of farm.

Our results showed that $58 \%$ of the surveyed farms regularly used in-feed or in-water antimicrobial prophylaxis and most of them administered more than one compound, with colistin, betalactams and tetracyclines being the most used drugs. In our opinion, these data reflect that mass prophylaxis is still seen as a first 


\section{$\square \quad$ No prophylaxis \\ $\square \quad$ Up to one drug \\ - Two or more drugs}

\begin{tabular}{|lcc|}
\hline Category & $\%$ & $\mathrm{n}$ \\
\hline$\square 0$ & 6.3 & 6 \\
$\square 1$ & 46.3 & 44 \\
$\square 2$ & 47.4 & 45 \\
\hline Total & $(100.0)$ & 95 \\
\hline \multicolumn{3}{|c}{ Production system }
\end{tabular}

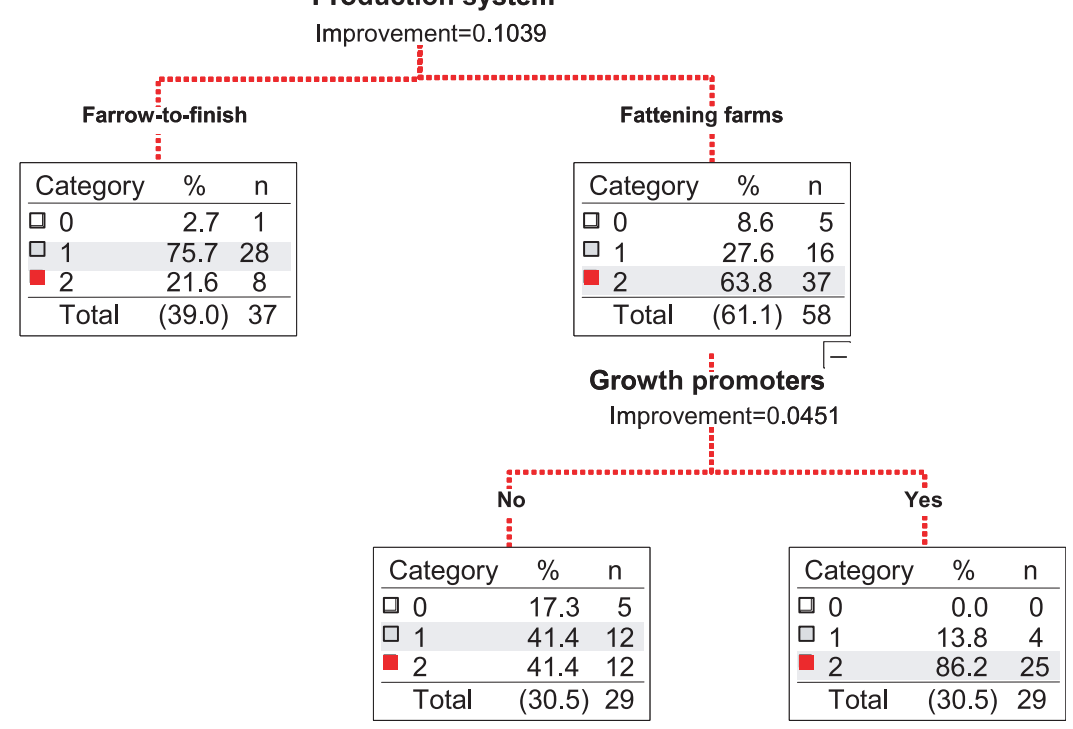

Figure 2. Regression tree profiling the use of in-feed and/or in-water antimicrobials in finishers in Catalonia to control respiratory diseases $(n=95)$. (A color version of this figure is available at www.edpsciences.org/vetres.)

line preventive measure. Also, most farms used the same compounds (colistin or tetracyclines) for mass treatments in the event of an outbreak of enteric or respiratory diseases. On the contrary, the reasons for the choice of compounds for prophylactic use is unclear since, in many instances, combinations of two or more drugs are used simultaneously without a definitive diagnosis of the farm pathogens nor a clear indication for the need of a combined treatment.

The results of the logistic analysis indicated a large difference in the usage of antimicrobial prophylaxis between fattening units and farrow-to-finish farms: the first ones rely more on mass prophylaxis (more often and more drugs) as a preventive measure. In fattening farms, the turnover of pigs is higher and in many occasions animals come from multiple origins, both circumstances being risk factors for the introduction and spread of diseases. It seems reasonable to think that these circumstances are factors influencing the use of antimicrobials. Mass prophylaxis was also more likely on farms without changing facilities for workers. This variable is probably an indicator of poorly designed biosecurity measures that facilitate the entry and circulation of pathogens. Recently, Chauvin et al. [4] described similar observations in turkey flocks, where changing clothes and shoes before entering a facility is associated with a low antimicrobial consumption.

The regression tree analysis showed that administration of antimicrobial 


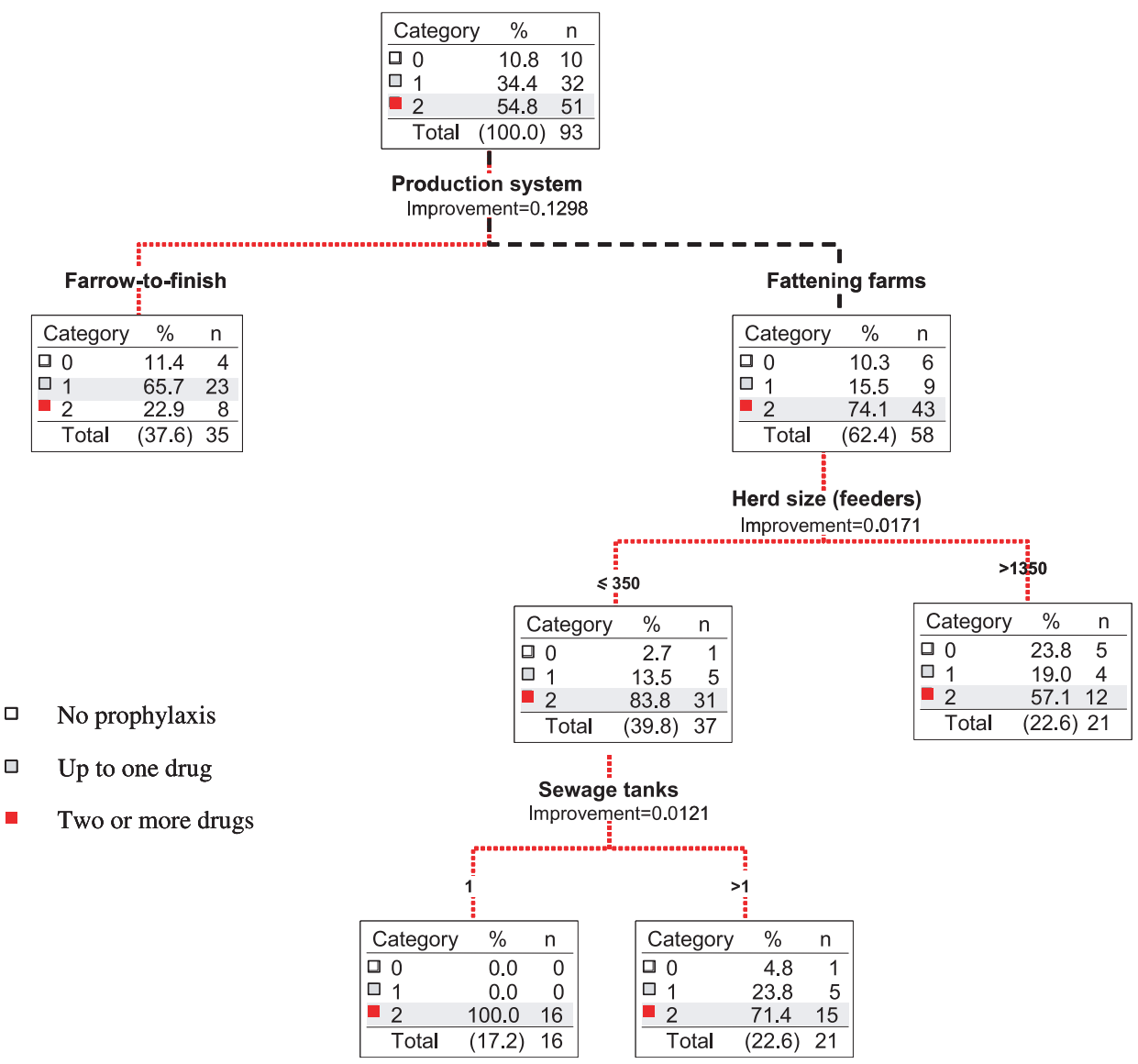

Figure 3. Regression tree profiling the use of in-feed and/or in-water feed antimicrobials in finishers in Catalonia to control outbreaks of enteric disease $(n=93)$. (A color version of this figure is available at www.edpsciences.org/vetres.)

prophylaxis was also related to the use of growth promoters. According to these results, we can hypothesize that those farms that did not use growth promoters did not present a higher incidence of diseases and did not use higher amounts of antimicrobials with a prophylactic aim. This would agree with other observations indicating that banning of growth promoters did not produce a long-term increase in the usage of antimicrobial agents in pigs or poultry $[11,19]$. This relationship between growth promoters and antimicrobials sug- gests a farm profile that can be qualified, so to say it, as "antimicrobial-friendly" and may suggest a higher use of growth promoters in farms with low productivity where the improvement produced by growth promoters would be sounder. As seen in the logistic regression, it is tempting to relate this with poor husbandry methods or deficient biosecurity measures (the lack of changing facilities might be an indicator of such deficiencies). Also, farms with a deficient productive management are likely to be more prone to disease. 
As observed in the logistic analysis, the higher usage of antimicrobial prophylaxis correlated to fattening farms. In addition, on farms that did not use growth promoters, the use of antimicrobials was related to higher mortalities and could be seen as a response to health problems that were not solved by other means.

The present survey also showed that most farms also apply empirical mass treatments when confronted with a respiratory or enteric outbreak and did not perform laboratory diagnostic. In our opinion, this represents a serious concern. It could be the cause of therapeutic failures and can contribute significantly to the development of antimicrobial resistance, particularly in enteric pathogens if treatments are delivered by the oral route.

In the logistic regression analysis, the only factor related to the use of more than one compound for mass treatment of respiratory outbreaks was the administration of growth promoters. As seen in the regression tree analysis, this relationship is stronger in fattening farms than on farrowto-finish farms. The meaning of this relationship is not clear but could reinforce the notion of the existence of a set of "antimicrobial-friendly" farms, especially in fattening units.

Mass treatments in enteric disease outbreaks were also a common practice. The number of drugs used for such treatments was related to the type of operation and the use of mass prophylaxis, showing again that fattening farms are more likely to use a higher number of antimicrobial compounds than farrow-to-finish farms. In the regression tree analysis, small fattening operations ( $<1350$ pigs) with several sewage tanks draw the profile of farms using more antimicrobial compounds to control enteric problems. This profile might reflect less professionalised farms in contrast to more modern ones that probably have a greater concern about preventive measures.
The regression tree analysis is used to build-up models for classification and can be a complementary or even an alternative technique to logistic regression [16]. This method allows detecting variables than can have an effect in a part of the cases (i.e. fattening farms), but not in another subset (i.e. farrow-to-finish farms), and in consequence is a good tool to better know the importance of some variables in different conditions. The use of regression trees in biomedical disciplines is increasing and it is being used to classify probable outcomes for diseases $[5,18]$ or to figure out the relevance of genetic markers [13]. This technique is also useful to classify behaviour or habitude patterns that allow the identification of target segments of the population to whom a specific message can be addressed effectively [1] having thus a sociologic value. The information about alternatives to growth promoters after the ban of their use, would be more effective if it is addressed to fattening farms and could be complemented with a campaign to reduce the usage of antimicrobials.

In the context of our study, this sociologic value is also important. When our results are taken together, it can be seen that combinations of two or more antimicrobials are used on a high proportion of farms, and the gross image that arises is that antimicrobial usage is probably higher than needed. Also it can be speculated that the population can be divided between those farms that "like antimicrobials" (farms that used growth promoters, and combined several drugs to treat conventional problems) and those who tend to use antimicrobial agents only when indicated because of a disease outbreak. These profiles seem to correspond roughly to fattening and farrow-to-finish farms, respectively, and might also reflect the greater stability of diseases in closed operations versus the more dynamic pattern of fattening farms if these latter are not fully batchoperated. These results could be useful to 
design informative campaigns, directed to farmers and veterinarians, on the rationale use of antimicrobial drugs.

\section{ACKNOWLEDGEMENTS}

Our grateful thanks to the Spanish Ministry of Education and Science for funding project AGF99-1234 that supported this study.

\section{REFERENCES}

[1] Albrecht T.L., Bryant C., Advances in segmentation modeling for health communication and social marketing campaigns, J. Health Commun. (1996) 1:65-80.

[2] Asai T., Kojima A., Harada K., Ishihara K., Takahashi T., Tamura Y., Correlation between the usage volume of veterinary therapeutic antimicrobials and resistance in Escherichia coli isolated from the feces of food-producing animals in Japan, Jpn. J. Infect. Dis. (2005) 58:369-372.

[3] Chauvin C., Beloeil P.A., Orand J.P., Sanders P., Madec F., A survey of group-level antibiotic prescriptions in pig production in France, Prev. Vet. Med. (2002) 55:109-120.

[4] Chauvin C., Bouvarel I., Belœil P.-A., Orand J.-P., Guillemot D., Sanders P., A pharmacoepidemiological analysis of factors associated with antimicrobial consumption level in turkey broiler flocks, Vet. Res. (2005) 36:199-211.

[5] Cornfield D.B., Palazzo J.P., Schwartz G.F., Goonewardene S.A., Kovatich A.J., Chervoneva I., Hyslop T., Schwarting R., The prognostic significance of multiple morphologic features and biologic markers in ductal carcinoma in situ of the breast: a study of a large cohort of patients treated with surgery alone, Cancer (2004) 100:2317-2327.

[6] Dewey C.E., Cox B.D., Straw B.E., Bush E.J., Hurd S., Use of antimicrobials in swine feeds in the United States, Swine Health Prod. (1999) 7:19-25.
[7] Dunlop R.H., McEwen S.A., Meek A.H., Friendship R.A., Clarke R.C., Black W.D., Antimicrobial drug use and related management practices among Ontario swine producers, Can. Vet. J. (1998) 39:87-96.

[8] Emborg H.D., Andersen J.S., Seyfarth A.M., Andersen S.R., Boel J., Wegener H.C., Relations between the occurrence of resistance to antimicrobial growth promoters among Enterococcus faecium isolated from broilers and broiler meat, Int. J. Food Microbiol. (2003) 84:273-284.

[9] Emborg H.D., Andersen J.S., Seyfarth A.M., Wegener H.C., Relations between the consumption of antimicrobial growth promoters and the occurrence of resistance among Enterococcus faecium isolated from broilers, Epidemiol. Infect. (2004) 132:95-105.

[10] Garnier F., Gambarotto K., Denis F., Ploy M.C., Molecular study of vancomycinresistant enterococci isolated from humans and from food in a cattle-rearing area of France, J. Antimicrob. Chemother. (2004) 54:236-239.

[11] Grave K., Jensen V.F., Odensvik K., Wierup M., Bangen M., Usage of veterinary therapeutic antimicrobials in Denmark, Norway and Sweden following termination of antimicrobial growth promoter use, Prev. Vet. Med. (2006) 75:123-132.

[12] Hayes J.R., Wagner D.D., English L.L., Carr L.E., Joseph S.W., Distribution of streptogramin resistance determinants among Enterococcus faecium from a poultry production environment of the USA, J. Antimicrob. Chemother. (2005) 55:123-126.

[13] Hizer S.E., Wright T.M., Garcia D.K., Genetic markers applied in regression tree prediction models, Anim. Genet. (2004) 35:50-52.

[14] Kelly L., Smith D.L., Snary E.L., Johnson J.A., Harris A.D., Wooldridge M., Morris J.G. Jr., Animal growth promoters: to ban or not to ban? A risk assessment approach, Int. J. Antimicrob. Agents (2004) 24:205-212.

[15] Lee J.H., Methicillin (Oxacillin)-resistant Staphylococcus aureus strains isolated from major food animals and their potential transmission to humans, Appl. Environ. Microbiol. (2003) 69:6489-6494. 
[16] Lemon S.C., Roy J., Clark M.A., Friedmann P.D., Rako W., Classification and regression tree analysis in public health: methodological review and comparison with logistic regression, Ann. Behav. Med. (2003) 26:172-181.

[17] Thrusfield M., Ortega C., de Blas I., Noordhuizen J.P., Frankena K., WIN EPISCOPE 2.0: improved epidemiological software for veterinary medicine, Vet. Rec. (2001) 148:567-572.
[18] Vogelsang H., Haas S., Hierholzer C., Berger U., Siewert J.R., Prauer H., Factors influencing survival after resection of pulmonary metastases from colorectal cancer, Br. J. Surg. (2004) 91:1066-1071.

[19] Wierup M., The Swedish experience of the 1986 year ban of antimicrobial growth promoters, with special reference to animal health, disease prevention, productivity, and usage of antimicrobials, Microb. Drug Resist. (2001) 7:183-190. 